\title{
Green Synthesis of Silver Nanoparticles Using Leaf Extracts of Clitoria ternatea and Solanum nigrum and Study of Its Antibacterial Effect against Common Nosocomial Pathogens
}

\author{
Narayanaswamy Krithiga, Athimoolam Rajalakshmi, and Ayyavoo Jayachitra \\ Department of Plant Biotechnology, School of Biotechnology, Madurai Kamaraj University, Madurai 6250021, India \\ Correspondence should be addressed to Ayyavoo Jayachitra; jchitra21@gmail.com
}

Received 11 July 2014; Revised 16 January 2015; Accepted 16 January 2015

Academic Editor: Nikolai Khlebtsov

Copyright (C) 2015 Narayanaswamy Krithiga et al. This is an open access article distributed under the Creative Commons Attribution License, which permits unrestricted use, distribution, and reproduction in any medium, provided the original work is properly cited.

\begin{abstract}
Bionanotechnology has emerged up as integration between biotechnology and nanotechnology for developing biosynthetic and environmental friendly technology for synthesis of nanomaterials. Silver has been known to have effective bactericidal properties for centuries. Nowadays, silver based topical dressings have been widely used as a treatment for infection in burns, open wounds, and chronic ulcer. As the pathogenic organisms are getting evolved day by day due to mutation and gaining antibiotic resistance, an important industrial sector of nanoscience deals with the preparation and study of nanoparticles in antibacterial clothing, burn ointments, and coating for medical device. The size of nanomaterials is much smaller than that of most biological molecules and structures; therefore, nanomaterials can be useful in both in vivo and in vitro biomedical research application. The purpose of the study is to synthesize and characterize the plant mediated silver nanoparticles using Clitoria ternatea and Solanum nigrum. Further investigation of the shape and size of nanoparticle was done by X-ray diffraction and scanning electron microscopic studies. A silver nanoparticle at different concentration was assessed for its antibacterial effect, against various nosocomial pathogens.
\end{abstract}

\section{Introduction}

Nanotechnology is the fastest growing area of manufacturing in the world today and there is an increasingly frantic search for new nanomaterials and methods to make them. It has been well known that living cells are the best examples of machines that operate at the nanolevel and perform a number of jobs ranging from generation of energy to extraction of targeted materials at very high efficiency [1].

One of the fields in which nanotechnology finds extensive applications is nanomedicine, an emerging new field which is an outcome of fusion of nanotechnology and medicine. Medicine is no more physician job exclusively, the materials and devices designed at the level of nanoscale are for diagnosis, treatment, preventing diseases and traumatic injury, relieving pain and also in the overall preservation and improvement of health [2]. Nanotechnology can improve our understanding of living cells and of molecular level interactions. A number of nanoparticles based therapeutics have been approved clinically for infections, vaccines, and renal diseases [3]. Oligodynamic silver having antimicrobial efficacy extends well beyond its virotoxicity and it has lethal effects spanned across all microbial domains [4]. The application of silver nanoparticles in drug delivery, drug discovery, and new drug therapies has declared war on many dreadful diseases and they use the body natural transport pathway and natural mechanism of uptake of the drug by the diseased cells [5].

Nanoparticles can be synthesized using various approaches including chemical, physical, and biological approaches. Although chemical method of synthesis requires short period of time for synthesis of large quantity of nanoparticles, this method requires capping agents for size stabilization of the nanoparticles. Chemicals used for nanoparticles synthesis and stabilization are toxic and lead to non-eco-friendly byproducts. The need for environmental nontoxic synthetic protocols for nanoparticles synthesis leads to the developing interest in biological approaches which 
are free from the use of toxic chemicals as byproducts. Thus, there is an increasing demand for "green nanotechnology." Many biological approaches for both extracellular and intracellular nanoparticles synthesis have been reported till date using microorganisms including bacteria [6], fungi $[7,8]$, and plants [9-11].

Plants provide a better platform for nanoparticle synthesis as they are free from toxic chemicals and provide natural capping agents. Moreover, use of plant extracts also reduces the cost of microorganisms isolation and culture media enhancing the cost competitive feasibility over nanoparticles synthesis by microorganisms [12].

Nanobiotechnology is the most active area of research in modern material science. Nanoparticles exhibit completely new or improved properties based on specific characteristics such as size, distribution, and morphology [13].

Antibacterial activity of the silver containing materials is used in medicine to reduce infections in burn treatment [14] and arthroplasty [15], as well as prevent bacteria colonization on prostheses [16], catheters [17], vascular grafts, dental materials [18], stainless steel materials [19], and human skin [20].

Silver nanoparticles are widely used for its unique properties in catalysis, chemical sensing, biosensing, photonics, electronics, and pharmaceuticals [21]. Silver nanoparticles have a great potential for use in biological including antimicrobial activity [22]. Antimicrobial capability of silver nanoparticles allows them to be suitably employed in numerous household products such as textiles, food storage containers, home appliances, and medical devices [23]. Silver is an effective antimicrobial agent which exhibits low toxicity [24]. The most important application of silver and silver nanoparticles is in medical industry such as tropical ointments to prevent infection against burn and open wounds [25]. Silver nanoparticles play a profound role in the field of biology and medicine due to their attractive physiochemical properties. Silver products have long been known to have strong inhibitory and bactericidal effects, as well as a broad spectrum of antimicrobial activities, which has been used for centuries to prevent and treat various diseases, most notably infections [26]. Silver nanoparticles are reported to possess antifungal, anti-inflammatory, antiviral, antiangiogenesis, and antiplatelet activity [27].

\section{Materials and Methods}

2.1. Plant Material. Clitoria ternatea habit is a twining shrub with alternate imparipinnate leaves. About their flowers are solitary or in pairs. The classification of Clitoria ternatea is given in the following:

\author{
family: Fabaceae; \\ subfamily: Faboideae; \\ genus: Clitoria; \\ species: ternatea; \\ botanical name: Clitoria ternatea; \\ common name: sankupushpam.
}

Solanum nigrum habit dicot weed in Solanaceae family is an African paediatric plant used for several aliments that are responsible for infant mortality especially to convulsions. It is an annual branched herb of up to $90 \mathrm{~cm}$ high dull dark green leaves, juicy, ovate, or lanceolate, and toothless to slightly toothed on the margins. The classification of Solanum nigrum is given as follows:
family: Solanaceae;
genus: Solanum;
species: nigrum;
botanical name: Solanum nigrum;
common name: night shade.

2.1.1. Collection and Preparation of Plant Materials. Fresh leaves of two different plants, that is, Clitoria ternatea and Solanum nigrum, free from diseases were collected from Madurai and then washed thoroughly 2-3 times with tap water and once with sterile water. $20 \mathrm{~g}$ of fresh leaves was finely chopped and added to $100 \mathrm{~mL}$ of distilled water and stirred at $60^{\circ} \mathrm{C}$ for $1 \mathrm{~h}$. After boiling, the mixture was cooled and filtered with Whatman paper number 1 . Filtrate was collected.

2.2. Synthesis of Silver Nanoparticles [12]. $0.1 \mathrm{M}$ of aqueous solution of silver nitrate $\left(\mathrm{AgNO}_{3}\right)$ was prepared and used for the synthesis of silver nanoparticles. $5 \mathrm{~mL}$ of leaf extract of Clitoria ternatea and Solanum nigrum was added to $45 \mathrm{~mL}$ of $0.1 \mathrm{M} \mathrm{AgNO} 3$ solution for bioreduction process at room temperature.

2.3. UV-Visible Absorbance Spectroscopy [26]. UV-Visible spectroscopy analysis was carried out on a Systronic UVVisible absorption spectrophotometer 117 with a resolution of $\pm 1 \mathrm{~nm}$ between 200 and $1000 \mathrm{~nm}$ processing a scanning speed of $200 \mathrm{~nm} / \mathrm{min}$. Equal amounts of the suspension $(0.5 \mathrm{~mL})$ were taken and analysed at room temperature. The progress of the reaction between metal ions and the leaf extract was monitored by UV-Visible spectra of silver nanoparticles in aqueous solution with different wavelength in nanometers from 340 to $800 \mathrm{~nm}$. The reduction of silver ions and formation of silver nanoparticles occurred within an hour of reaction. Control was maintained by using $\mathrm{AgNO}_{3}$.

2.4. Fourier Transforms Infrared Spectroscopy (FTIR). For FTIR measurements, the synthesized silver nanoparticles solution was centrifuged at $10000 \mathrm{rpm}$ for 30 minutes. The pellet was washed thrice with $5 \mathrm{~mL}$ of deionised water to get rid of the free proteins or enzymes that are not capping the silver nanoparticles. The pellet was dried by using vacuum drier. It was analysed by FTIR.

2.5. X-Ray Diffraction [28]. A thin film of the silver nanoparticle was made by dipping a glass plate in a solution and carried out for X-ray diffraction studies. The crystalline silver nanoparticle was calculated from the width of the XRD peaks 


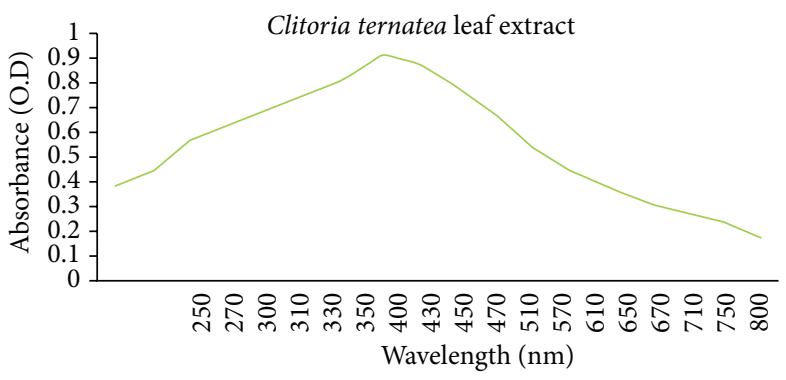

(a)

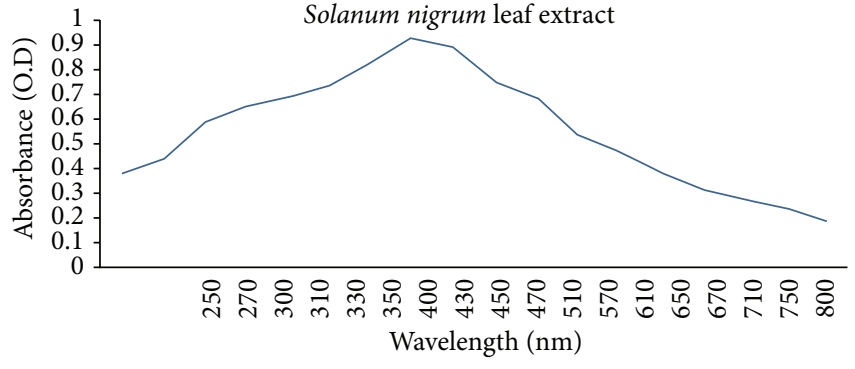

(b)

FIGURE 1: (a) UV-VIS spectroscopy for silver nanoparticles synthesised using Clitoria ternatea leaves extracts. (b) UV-VIS spectroscopy for silver nanoparticles synthesised using Solanum nigrum leaves extracts.

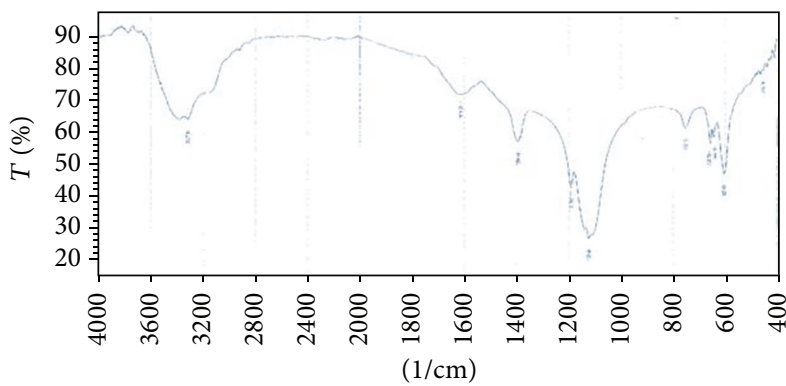

(a)

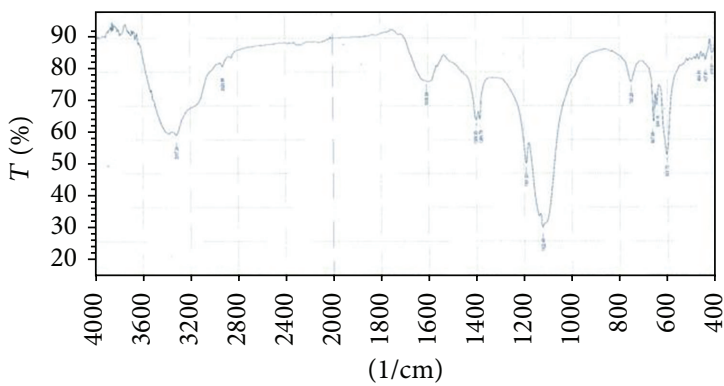

(b)

FIGURE 2: (a) FTIR spectrum of silver nanoparticles synthesized by using the leaf extract of Clitoria ternatea. (b) FTIR spectrum of silver nanoparticles synthesized by using the leaf extract of Solanum nigrum.

and the average size of the nanoparticles can be estimated using the Debye-Scherrer equation [29]:

$$
D=\frac{k \lambda}{\beta \cos \theta},
$$

where $D=$ thickness of the nanocrystal, $k=$ constant, $\lambda=$ wavelength of X-rays, $\beta=$ width at half maxima of (111) reflection at Bragg's angle $2 \theta$, and $\theta=$ Bragg angle.

The size of the silver nanoparticle was made from the line broadening of the (111) reflection using the Debye-Scherrer formula. According to the formula, constant $(k)=0.94$ and wavelength $(\lambda)=1.5406 \times 10^{-10}$.

2.6. Scanning Electron Microscopy [30]. The pellet was subjected for SEM analysis. Thin films of the sample were prepared on a carbon coated copper grid by just dropping a very small amount of the sample on the grid; extra solution was removed using a blotting paper and then the film on the SEM grid was allowed to dry for analysis.

2.7. Antibacterial Assays [31]. The antibacterial assays were done pathogens like nosocomial pathogens such as Bacillus subtilis, Staphylococcus aureus, Streptococcus pyogenes, Escherichia coli, Pseudomonas aeruginosa, and Klebsiella aerogenes by standard disc diffusion method. Briefly Luria Bertani (LB) broth/agar medium was used to cultivate bacteria. Fresh overnight culture of inoculum $(100 \mu \mathrm{L})$ of each culture was spread on to Mueller Hinton Agar (MHA) plates. Sterile paper disc of $5 \mathrm{~mm}$ diameter containing $30 \mu \mathrm{g} / \mathrm{mL}$ silver nanoparticles along with standard antibiotic $(30 \mu \mathrm{g} / \mathrm{mL})$ containing discs was placed in each plate as control. The plates were incubated at $37^{\circ} \mathrm{C}$ overnight. Next day the inhibition zones around the discs were measured.

\section{Results}

The reduction of silver nitrate using the plant leaf extract was viewed by the colour change in the reaction solutions (Figures 6(a) and 6(b)). In UV-V is spectra recorded for the reaction solution of reduced silver nitrate by leaf extract of Clitoria ternatea and Solanum nigrum (Figures 1(a) and 1(b)). The maximum absorbance peak was seen at 420 and $440 \mathrm{~nm}$ for Clitoria ternatea and Solanum nigrum, respectively.

FTIR measurements were carried out to identify the possible biomolecules responsible for the capping and efficient stabilization of the silver nanoparticles synthesized by the plant extracts. Figures 2(a) and 2(b) show the leaf broth of Clitoria ternatea and Solanum nigrum, respectively. Absorbance bands of Clitoria ternatea were observed at $3317.34 \mathrm{~cm}^{-1}$ assigned to $\mathrm{O}-\mathrm{H}$ (s) stretch, $3317.34 \mathrm{~cm}^{-1}$ assigned to $\mathrm{O}-\mathrm{H}(\mathrm{s})$ stretch, $1614.31 \mathrm{~cm}^{-1}$ assigned to $\mathrm{C}=\mathrm{C}$ aromatic stretch, $1394.44 \mathrm{~cm}^{-1}$ assigned to $\mathrm{C}-\mathrm{H}$ alkenes stretch, $1191.93 \mathrm{~cm}^{-1}$ assigned to $\mathrm{C}-\mathrm{N}$ amines stretch, and $752.19 \mathrm{~cm}^{-1}$ and $655.75 \mathrm{~cm}^{-1}$ assigned to $\mathrm{C}-\mathrm{H}$ alkenes stretch. Absorbance bands of Solanum nigrum were observed at $3317.34 \mathrm{~cm}^{-1}$ assigned to $\mathrm{O}-\mathrm{H}$ (s) stretch, $2933.88 \mathrm{~cm}^{-1}$ 


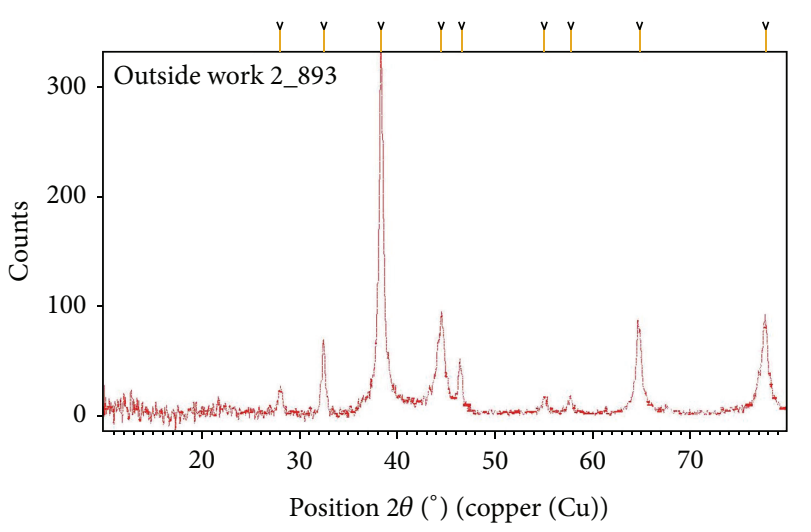

\begin{tabular}{cccccc}
\hline $\begin{array}{c}\text { Position } \\
2 \theta\left(^{\circ}\right)\end{array}$ & $\begin{array}{c}\text { Height } \\
(\mathrm{cts})\end{array}$ & $\begin{array}{c}\text { FWHM } \\
2 \theta\left(^{\circ}\right)\end{array}$ & $\begin{array}{c}\text { d-spacing } \\
(\AA)\end{array}$ & Rel. int. (\%) & Particle size \\
\hline 28.0784 & 21.71 & 0.5353 & 3.17800 & 7.00 & 15.98 \\
32.5020 & 64.99 & 0.3346 & 2.75486 & 20.94 & 25.84 \\
38.3386 & 310.37 & 0.3011 & 2.34783 & 100.00 & 29.18 \\
44.5440 & 78.60 & 0.5353 & 2.03411 & 25.32 & 16.75 \\
46.5090 & 39.65 & 0.4015 & 1.95265 & 12.77 & 22.50 \\
57.7165 & 14.33 & 0.5353 & 1.59732 & 4.62 & 17.70 \\
64.7555 & 73.34 & 0.5353 & 1.43966 & 23.63 & 18.36 \\
77.6973 & 76.20 & 0.6528 & 1.22803 & 24.55 & 16.32 \\
\hline
\end{tabular}

Average particle size of the nanoparticles: 20

(a)

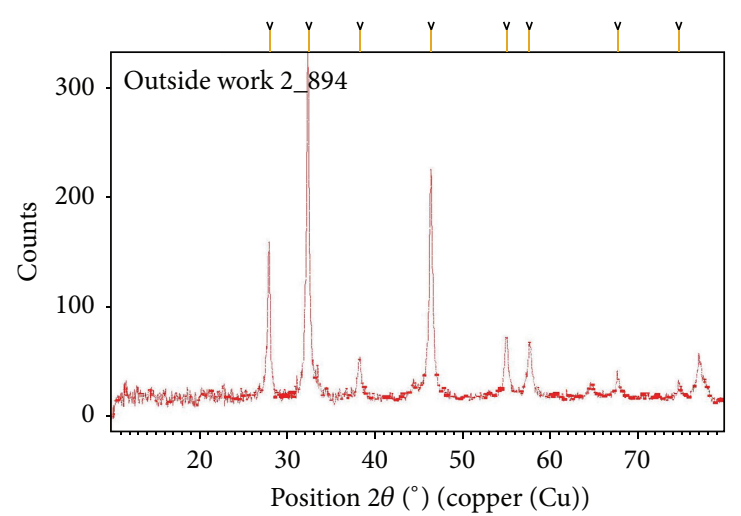

\begin{tabular}{lccccc}
\hline $\begin{array}{c}\text { Position } \\
2 \theta\left(^{\circ}\right)\end{array}$ & $\begin{array}{c}\text { Height } \\
(\mathrm{cts})\end{array}$ & $\begin{array}{c}\text { FWHM } \\
2 \theta\left(^{\circ}\right)\end{array}$ & $\begin{array}{c}\text { d-spacing } \\
(\AA)\end{array}$ & Rel. int. (\%) & Particle size \\
\hline 28.0437 & 132.93 & 0.2007 & 3.18185 & 44.71 & 42.63 \\
32.4911 & 297.33 & 0.1840 & 2.75576 & 100.00 & 46.99 \\
38.3743 & 32.86 & 0.5353 & 2.34574 & 11.05 & 16.42 \\
46.4844 & 188.60 & 0.2175 & 1.95363 & 63.43 & 41.53 \\
55.1135 & 49.99 & 0.3680 & 1.66643 & 16.81 & 25.44 \\
57.6944 & 46.58 & 0.3346 & 1.59788 & 15.66 & 28.32 \\
67.7475 & 14.42 & 0.8029 & 1.38318 & 4.85 & 12.45 \\
74.7433 & 5.61 & 0.9792 & 1.26906 & 1.89 & 10.66 \\
\hline
\end{tabular}

Average particle size of the nanoparticles: 28

(b)

FIGURE 3: (a) XRD pattern of silver nanoparticles synthesized using Clitoria ternatea leaf extract. (b) XRD pattern of silver nanoparticles synthesized using Solanum nigrum leaf extra.

assigned to $\mathrm{C}-\mathrm{H}$ (s) stretch, $1606.59 \mathrm{~cm}^{-1}$ assigned to $\mathrm{C}=\mathrm{C}$ aromatic stretch, $1394.44 \mathrm{~cm}^{-1}$ assigned to $\mathrm{C}-\mathrm{H}$ alkenes stretch, $1191.93 \mathrm{~cm}^{-1}$ assigned to $\mathrm{C}-\mathrm{N}$ amines stretch, $1122.49 \mathrm{~cm}^{-1}$ assigned to $\mathrm{C}-\mathrm{N}$ amines stretch, and $752.19 \mathrm{~cm}^{-1}$ and $655.75 \mathrm{~cm}^{-1}$ assigned to $\mathrm{C}-\mathrm{H}$ alkenes stretch.

The silver oxide molecules formed are necessarily subjected to XRD analysis for the measurement of size of these particles. Figures 3(a) and 3(b) show the XRD pattern obtained for the silver nanoparticles synthesized using the leaf extract of Clitoria ternatea and Solanum nigrum. The intense peak of nanoparticles $28,33,38,44,46,55,58,65$, and 77 in Clitoria ternatea and 28, 32, 39, 45, 55, 57, 65, 69, 75, and 77 in Solanum nigrum appeared which are indexed as crystalline silver. The sharpening of the peaks clearly indicates that the particles are the spherical nanoparticles. The average size of the silver nanoparticles is estimated by using Debye Scherrer's formula. The average of silver nanoparticles synthesized by Clitoria ternatea is $20 \mathrm{~nm}$ and average of silver nanoparticles synthesized by Solanum nigrum is $28 \mathrm{~nm}$.

The silver nanoparticles synthesized using Clitoria ternatea and Solanum nigrum leaf extract were optimized by various parameters such as temperature, $\mathrm{pH}$, and time. Figures 3(a) and 3(b) show that temperature increased and the rate of silver nanoparticles formation also increased. The size is reduced initially due to the reduction in aggregation of the growing nanoparticles. Figures 4(a) and 4(b) show that acidic condition suppresses the formation of silver nanoparticles but the basic condition enhances the formation of silver nanoparticles. Large nanoparticles were formed at lower $\mathrm{pH}(\mathrm{pH} 4)$, whereas small and highly dispersed nanoparticles were formed at high $\mathrm{pH}(\mathrm{pH} 9)$. At neutral $\mathrm{pH}$, the normal size of the nanoparticles is formed. Figures 5(a) and 5(b) show that duration of reaction increases and more silver nanoparticles are formed. Due to the instability of the silver nanoparticles formed, an optimum duration is required as silver nanoparticles agglomeration after the optimum duration resulting in larger particle sizes. The optimum time required for the completion of reaction from our study was 60 min.

Figures 4(a) and 4(b) show the SEM image of the silver nanoparticles in Clitoria ternatea and Solanum nigrum. Uniformly distributed silver nanoparticles on the surface of the cells are observed. However, it does not indicate that all the silver nanoparticles are bound to the surface of the cells, because those dispersing in the solution may also deposit on to the surface of the cells during the drying process, which is a necessary step before SEM.

\section{Discussion}

The formation of silver nanoparticles using plant leaf extract of Clitoria ternatea and Solanum nigrum was viewed by the colour change from colourless to yellowish brown. 


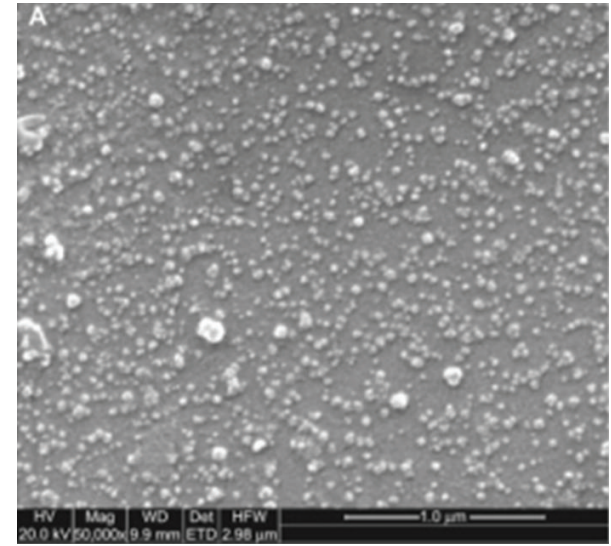

(a)

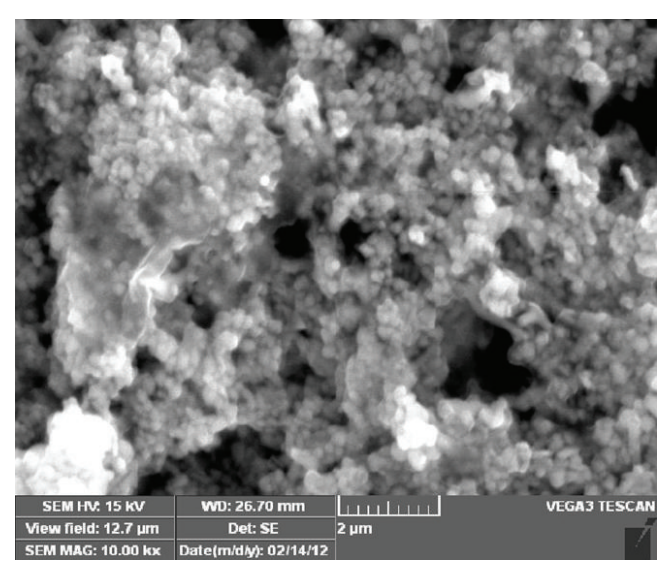

(b)

FIGURE 4: (a) SEM micrograph of silver nanoparticles synthesized by using the leaf extract of Clitoria ternatea. (b) SEM micrograph of silver nanoparticles synthesized by using the leaf extract of Solanum nigrum.

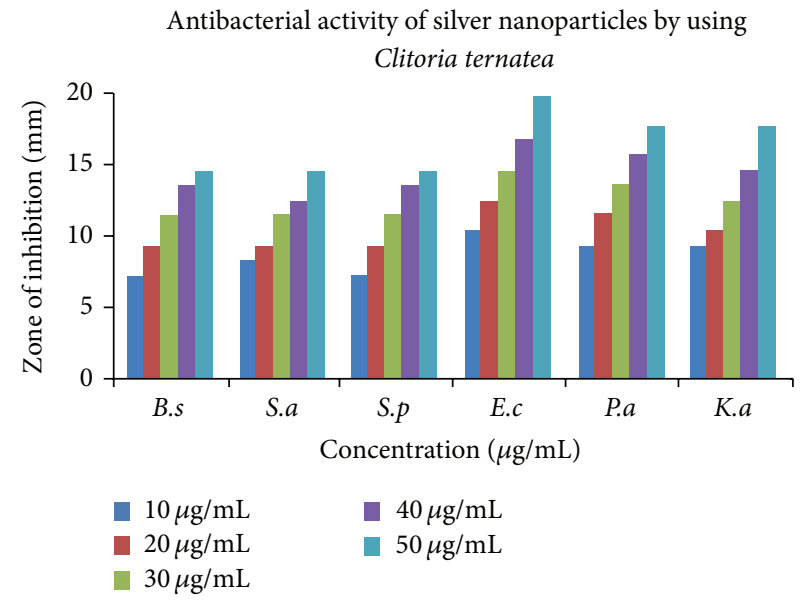

(a)

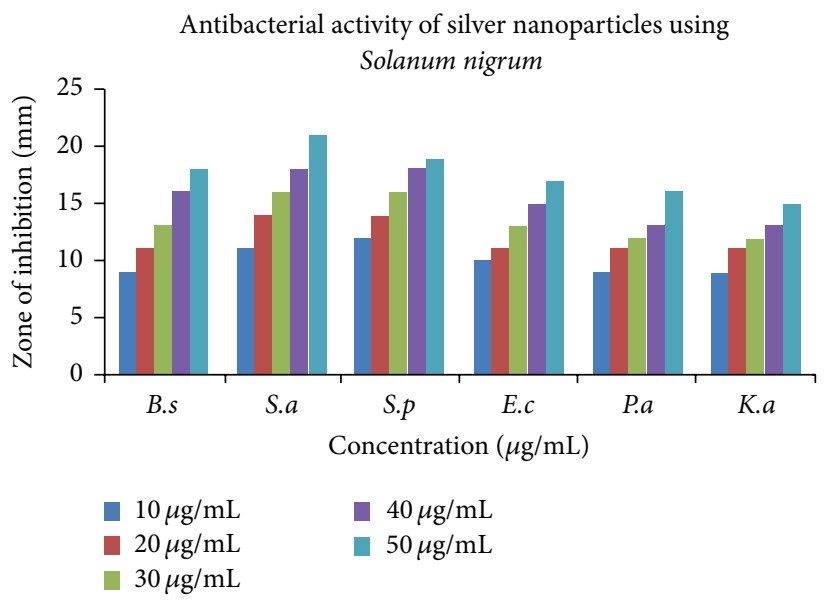

(b)

FIgURE 5: (a) The antibacterial activity of silver nanoparticles using Clitoria ternatea leaf extract against nosocomial pathogens and compared with the standard drug. (b) The antibacterial activity of silver nanoparticles using Solanum nigrum leaf extract against nosocomial pathogens and compared with the standard drug. B.s: Bacillus subtilis, S.a: Staphylococcus aureus, S.p: Streptococcus pyogenes, E.c: Escherichia coli, P.a: Pseudomonas aeruginosa, and K.a: Klebsiella aerogenes.

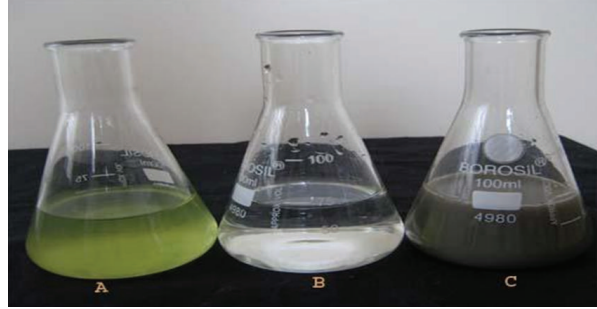

(a)

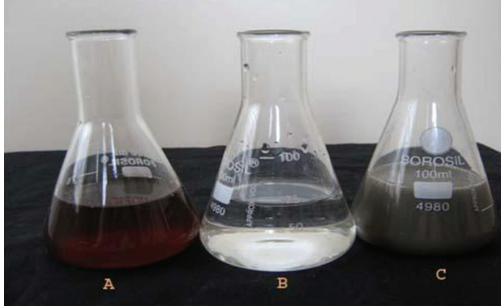

(b)

Figure 6: (a) Synthesis of silver nanoparticles using Clitoria ternatea: A-fresh leaf extract, B-silver nitrate before addition of leaf extract, and C-after addition of leaf extract. (b) Synthesis of silver nanoparticles using Solanum nigrum: A-fresh leaf extract, B-silver nitrate before addition of leaf extract, and C-after addition of leaf extract. 
Similarly, Sastry et al. [32] reported that the silver nanoparticles exhibited striking colours, from light yellow to brown. Further, Shankar et al. [33] reported that silver nanoparticles exhibited yellowish brown colour in aqueous solution due to excitation of surface plasmon vibrations in silver nanoparticles. By using UV-Visible spectrum the maximum absorbance peak for Clitoria ternatea and Solanum nigrum was seen at 420 and $440 \mathrm{~nm}$, respectively. Similarly, Prasad and Elumalai [34] reported that absorption spectra of silver nanoparticles formed in the reaction media have absorbance peak at $430-440 \mathrm{~nm}$. Veerasamy et al. [35] reported that absorption spectra of silver nanoparticles formed in the reaction media have absorbance peak at $438 \mathrm{~nm}$. Different parameters were optimized including temperature, $\mathrm{pH}$, and time which had been identified as factors affecting the yields of silver nanoparticles. Gilaki [36] reported that $\mathrm{pH}$, strength of elements, plant sources, time and incubation temperature nanoparticles synthesis reaction mixture, the synthesis methods, it is possible to create a wide range of different nanoparticles. FTIR analysis confirmed that the bioreduction of $\mathrm{Ag}^{+}$ions to silver nanoparticles is due to the reduction by capping material of plant extract. Similarly, Gole et al. [37] reported that proteins present in the extract can bind to silver nanoparticles through either free amino or carboxyl groups in the proteins. Prasad et al. [38] reported that the carboxyl $(-\mathrm{C}=\mathrm{O})$, hydroxyl $(-\mathrm{OH})$, and amine $(-\mathrm{NH})$ groups of leaf extracts are mainly involved in fabrication of silver nanoparticles. The average of silver nanoparticles is synthesized by $\mathrm{Cli}$ toria ternatea $20 \mathrm{~nm}$ and average of silver nanoparticles is synthesized by Solanum nigrum. The observed result was in accordance with the results of Raut et al. (2009), where the XRD studies reveal that silver nanoparticles are polydispersed and ranged in size from 10 to $50 \mathrm{~nm}$ with an average size of $27 \mathrm{~nm}$. Vivek et al. [39] reported that the silver nanoparticles synthesized from Gelidiella acerosa extract of XRD pattern reveal that the average size of the silver nanoparticles was $23 \mathrm{~nm}$. In this SEM micrograph, it was observed that the spherical nanoparticles were in the size ranging from 10 to $50 \mathrm{~nm}$ with a variety of morphology. Savithramma et al. [30] reported that relatively spherical shaped silver nanoparticles formed with diameter ranging from 30 to $40 \mathrm{~nm}$ in Boswellia ovalifoliolata and $40 \mathrm{~nm}$ in Shorea tumbuggaia.

Silver nanoparticles obtained from the Clitoria ternatea and Solanum nigrum have very strong inhibitory action against Pseudomonas aeruginosa followed by Staphylococcus aureus, Escherichia coli, and Streptococcus viridans. Similarly, Jain et al. [40] reported that antibacterial assay was done using Papaya fruit extract mediated silver nanoparticles on human pathogen, showing high toxicity against multidrug resistance bacteria. Kumar et al. [41] reported that silver nanoparticles were fairly toxic to Pseudomonas aeruginosa while they showed a moderate toxicity against $P$. vulgaris, E. coli, B. subtilis, and P. putida. However, nanoparticles exhibited low toxicity against $S$. typhi. The silver nanoparticles of Clitoria ternatea and Solanum nigrum were against the pathogens growth which was inhibited.

\section{Conclusion}

A critical need in the field of nanotechnology is the development of a reliable and eco-friendly process for synthesis of metallic nanoparticles. Nanoparticles are being viewed as fundamental building blocks of nanotechnology. Silver nanoparticles play a profound role in the field of biology and medicine due to their attractive physiochemical properties. In the present study, we have demonstrated that use of a natural, low cost biological reducing agent and Clitoria ternatea and Solanum nigrum leaves extracts can produce metal nanostructures, through efficient green nanochemistry methodology, avoiding the presence of toxic solvents and waste. The biosynthesized silver nanoparticles using Clitoria ternatea and Solanum nigrum leaves extract proved to be excellent against nosocomial pathogens and also compared to the fact that the silver nanoparticles of Clitoria ternatea showed higher activity than the silver nanoparticles of Solanum nigrum against nosocomial pathogens. The antimicrobial activity is well demonstrated by disc diffusion method. The present study showed a simple, rapid, and economical route to synthesize silver nanoparticles. The use of Clitoria ternatea and Solanum nigrum has the added advantage that this plant can be used by nanotechnology processing industries. Prepared nanoparticles can be used as bactericidal and, in wound healing, water purification, and also in the field of medicine due to these applications, this method is potentially exciting for the large-scale synthesis of nanoparticles.

\section{Conflict of Interests}

The authors declare that there is no conflict of interests regarding the publication of this paper.

\section{Acknowledgment}

The authors would like to thank Central Electrochemical Research Institute (CECRI), Karaikudi, Tamil Nadu, for their technical assistance in electron microscopy and XRD spectral analysis during the research.

\section{References}

[1] D. S. Goodsell, Bionanotechnology: Lessons from Nature, WileyLiss, Hoboken, NJ, USA, 2004.

[2] S. Pal, Y. K. Tak, and J. M. Song, "Does the antibacterial activity of silver nanoparticles depend on the shape of the nanoparticle? A study of the gram-negative bacterium Escherichia coli," Applied and Environmental Microbiology, vol. 73, no. 6, pp. 17121720, 2007.

[3] R. Malhotra, "Mass spectroscopy in life sciences," Current Science, vol. 98, pp. 140-145, 2010.

[4] N. Prabhu, D. T. Raj, K. Yamuna Gowri, S. Ayisha Siddiqua, and D. Joseph Puspha Innocent, "Synthesis of silver phyto nanoparticles and their antibacterial efficacy," Digest Journal of Nanomaterials and Biostructures, vol. 5, no. 1, pp. 185-189, 2010.

[5] S. Balaji, Nanobiotechnology, MJP Publishers, Chennai, India, 2010. 
[6] B. Nair and T. Pradeep, "Coalescence of nanoclusters and the formation of sub-micron crystallites assisted by Lactobacillus strains," Crystal Growth and Design, vol. 2, no. 4, pp. 293-298, 2002.

[7] P. Mukherjee, A. Ahmad, D. Mandal et al., "Fungus-mediated synthesis of silver nanoparticles and their immobilization in the mycelial matrix: a novel biological approach to nanoparticle synthesis," Nano Letters, vol. 1, no. 10, pp. 515-519, 2001.

[8] N. Durán, P. D. Marcato, O. L. Alves, G. I. H. De Souza, and E. Esposito, "Mechanistic aspects of biosynthesis of silver nanoparticles by several Fusarium oxysporum strains," Journal of Nanobiotechnology, vol. 3, article no. 8, 2005.

[9] S. P. Chandran, M. Chaudhary, R. Pasricha, A. Ahmad, and M. Sastry, "Synthesis of gold nanotriangles and silver nanoparticles using Aloevera plant extract," Biotechnology Progress, vol. 22, no. 2, pp. 577-583, 2006.

[10] S. Li, Y. Shen, A. Xie et al., "Green synthesis of silver nanoparticles using Capsicum annuum L. extract," Green Chemistry, vol. 9, no. 8, pp. 852-858, 2007.

[11] J. Huang, Q. Li, D. Sun et al., "Biosynthesis of silver and gold nanoparticles by novel sundried Cinnamomum camphora leaf," Nanotechnology, vol. 18, no. 10, Article ID 105104, 2007.

[12] S. Garima, B. Riju, K. Kunal, R. S. Ashish, and P. S. Rajendra, "Biosynthesis of silver nanoparticles using Ocimum sanctum (Tulsi) leaf extract and screening its antimicrobial activity," Journal of Nanoparticle Research, vol. 13, no. 7, pp. 2981-2988, 2011.

[13] A. Singh, D. Jain, M. K. Upadhyay, N. Khandelwal, and H. N. Verma, "Green synthesis of silver nanoparticles using Argemone Mexicana leaf extract and evaluation of their antimicrobial activities," Digest Journal of Nanomaterials and Biostructures, vol. 5, no. 2, pp. 483-489, 2010.

[14] D. V. Parikh, T. Fink, K. Rajasekharan et al., "Antimicrobial silver/sodium carboxymethyl cotton dressings for burn wounds," Textile Research Journal, vol. 75, no. 2, pp. 134-138, 2005.

[15] V. Alt, T. Bechert, P. Steinrücke et al., "An in vitro assessment of the antibacterial properties and cytotoxicity of nanoparticulate silver bone cement," Biomaterials, vol. 25, no. 18, pp. 4383-4391, 2004.

[16] G. Gosheger, J. Hardes, H. Ahrens et al., "Silver-coated megaendoprostheses in a rabbit model-an analysis of the infection rate and toxicological side effects," Biomaterials, vol. 25, no. 24, pp. 5547-5556, 2004.

[17] M. E. Rupp, T. Fitzgerald, N. Marion et al., "Effect of silvercoated urinary catheters: efficacy, cost-effectiveness, and antimicrobial resistance," American Journal of Infection Control, vol. 32, no. 8, pp. 445-450, 2004.

[18] S. Ohashi, S. Saku, and K. Yamamoto, "Antibacterial activity of silver inorganic agent YDA filler," Journal of Oral Rehabilitation, vol. 31, no. 4, pp. 364-367, 2004.

[19] M. Bosetti, A. Massè, E. Tobin, and M. Cannas, "Silver coated materials for external fixation devices: in vitro biocompatibility and genotoxicity," Biomaterials, vol. 23, no. 3, pp. 887-892, 2002.

[20] H. J. Lee and S. H. Jeong, "Bacteriostasis and skin innoxiousness of nanosize silver colloids on textile fabrics," Textile Research Journal, vol. 75, no. 7, pp. 551-556, 2005.

[21] R. Sarkar, P. Kumbhakar, and A. K. Mitra, "Green synthesis of silver nanoparticles and its optical properties," Digest Journal of Nanomaterials and Biostructures, vol. 5, no. 2, pp. 491-496, 2010.
[22] N. Sap-Lam, C. Homklinchan, R. Larpudomlert, W. Warisnoicharoen, A. Sereemaspun, and S. T. Dubas, "UV irradiationinduced silver nanoparticles as mosquito larvicides," Journal of Applied Sciences, vol. 10, no. 23, pp. 3132-3136, 2010.

[23] C. Marambio-Jones and E. M. V. Hoek, "A review of the antibacterial effects of silver nanomaterials and potential implications for human health and the environment," Journal of Nanoparticle Research, vol. 12, no. 5, pp. 1531-1551, 2010.

[24] M. D. A. Farooqui, P. S. Chauhan, P. Krishnamoorthy, and J. Shaik, "Extraction of silver nanoparticles from the left extracts of clerodendrum incerme," Digest Journal of Nanomaterials and Biostructures, vol. 5, no. 1, pp. 43-49, 2010.

[25] M. Ip, S. L. Lui, V. K. M. Poon, I. Lung, and A. Burd, "Antimicrobial activities of silver dressings: an in vitro comparison," Journal of Medical Microbiology, vol. 55, no. 1, pp. 59-63, 2006.

[26] S. S. Shankar, A. Rai, A. Ahmad, and M. Sastry, "Controlling the optical properties of lemongrass extract synthesized gold nanotriangles and potential application in infrared-absorbing optical coatings," Chemistry of Materials, vol. 17, no. 3, pp. 566572, 2005.

[27] B. J. Wiley, S. H. Im, Z.-Y. Li, J. McLellan, A. Siekkinen, and Y. Xia, "Maneuvering the surface plasmon resonance of silver nanostructures through shape-controlled synthesis," Journal of Physical Chemistry B, vol. 110, no. 32, pp. 15666-15675, 2006.

[28] P. Prema, "Chemical mediated synthesis of silver nanoparticles and its potential antibacterial application," in Progress in Molecular and Environmental Bioengineering, chapter 6, pp. 151-166, InTech, 2010.

[29] Z. L. Wang, "Transmission electron microscopy and spectroscopy of nanoparticles," in Characterization of Nanophase Materials, Z. L. Wang, Ed., chapter 3, pp. 37-80, Wiley-VCH, Weinheim, Germany, 2000.

[30] N. Savithramma, M. Linga Rao, and P. Suvarnalatha Devi, "Evaluation of antibacterial efficacy of biologically synthesized silver Nanoparticles using stem barks of Boswellia ovalifoliolata Bal. and Henry and Shorea tumbuggaia Roxb," Journal of Biological Sciences, vol. 11, no. 1, pp. 39-45, 2011.

[31] A. W. Bauer, W. W. M. Kirby, J. C. Sherris, and M. Turck, "Antibiotic susceptibility testing by a standardized single disk method," The American Journal of Clinical Pathology, vol. 45, no. 4, pp. 493-496, 1966.

[32] M. Sastry, A. Ahmad, M. I. Khan, and R. Kumar, "Biosynthesis of metal nanoparticles using fungi and actinomycetes," Current Science, vol. 85, no. 2, pp. 202-206, 2003.

[33] S. S. Shankar, A. Ahmad, R. Pasricha, and M. Sastry, "Bioreduction of chloroaurate ions by geranium leaves and its endophytic fungus yields gold nanoparticles of different shapes," Journal of Materials Chemistry, vol. 13, no. 7, pp. 1822-1826, 2003.

[34] T. N. V. K. Prasad and E. K. Elumalai, "Biofabrication of Ag nanoparticles using Moringa oleifera leaf extract and their antimicrobial activity," Asian Pacific Journal of Tropical Biomedicine, vol. 1, no. 6, pp. 439-442, 2011.

[35] R. Veerasamy, T. Z. Xin, S. Gunasagaran et al., "Biosynthesis of silver nanoparticles using mangosteen leaf extract and evaluation of their antimicrobial activities," Journal of Saudi Chemical Society, vol. 15, no. 2, pp. 113-120, 2011.

[36] M. Gilaki, "Biosynthesis of silver nanoparticles using plant extracts," Journal of Biological Sciences, vol. 10, no. 5, pp. 465467, 2010.

[37] A. Gole, C. Dash, V. Ramakrishnan et al., "Pepsin-gold colloid conjugates: preparation, characterization, and enzymatic activity," Langmuir, vol. 17, no. 5, pp. 1674-1679, 2001. 
[38] K. S. Prasad, D. Pathak, A. Patel et al., "Biogenic synthesis of silver nanoparticles using Nicotiana tobaccum leaf extract and study of their antibacterial effect," African Journal of Biotechnology, vol. 10, no. 41, pp. 8122-8130, 2011.

[39] M. Vivek, P. S. Kumar, S. Steffi, and S. Sudha, "Biogenic silver nanoparticles by Gelidiella acerosa extract and their antifungal effects," Avicenna Journal of Medical Biotechnology, vol. 3, no. 3, pp. 143-148, 2011.

[40] D. Jain, H. Kumar Daima, S. Kachhwaha, and S. L. Kothari, "Synthesis of plant-mediated silver nanoparticles using papaya fruit extract and evaluation of their anti microbial activities," Digest Journal of Nanomaterials and Biostructures, vol. 4, no. 3, pp. 557-563, 2009.

[41] P. Kumar, S. S. Selvi, A. L. Prabha, K. P. Kumar, R. S. Ganeshkumar, and M. Govindaraju, "Synthesis of silver nanoparticles from Sargassum tenerrimum and screening phytochemicals for its antibacterial activity," Nano Biomedicine and Engineering, vol. 4, no. 1, pp. 12-16, 2012. 

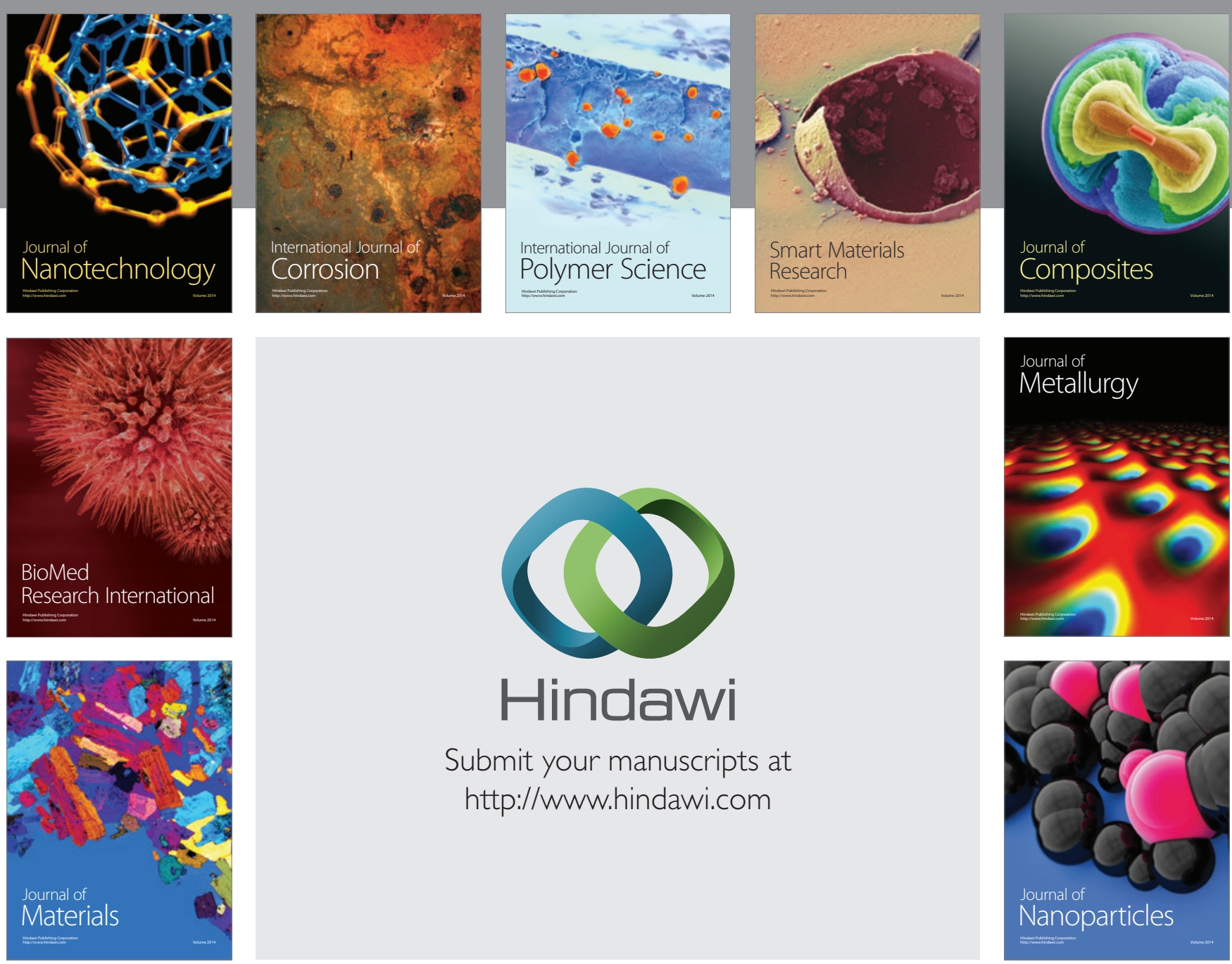

Submit your manuscripts at http://www.hindawi.com
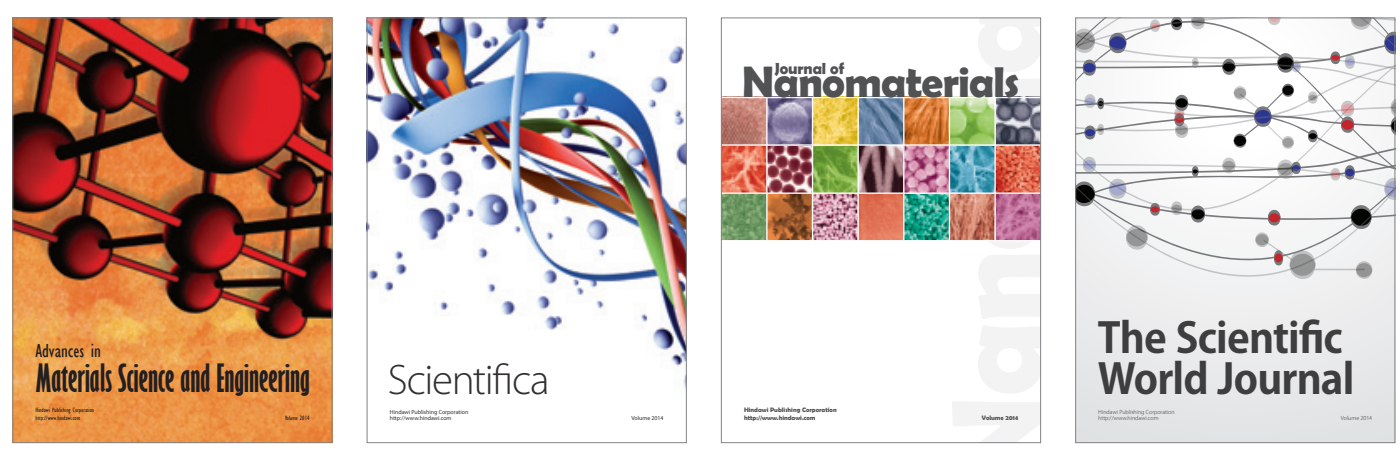

\section{The Scientific World Journal}
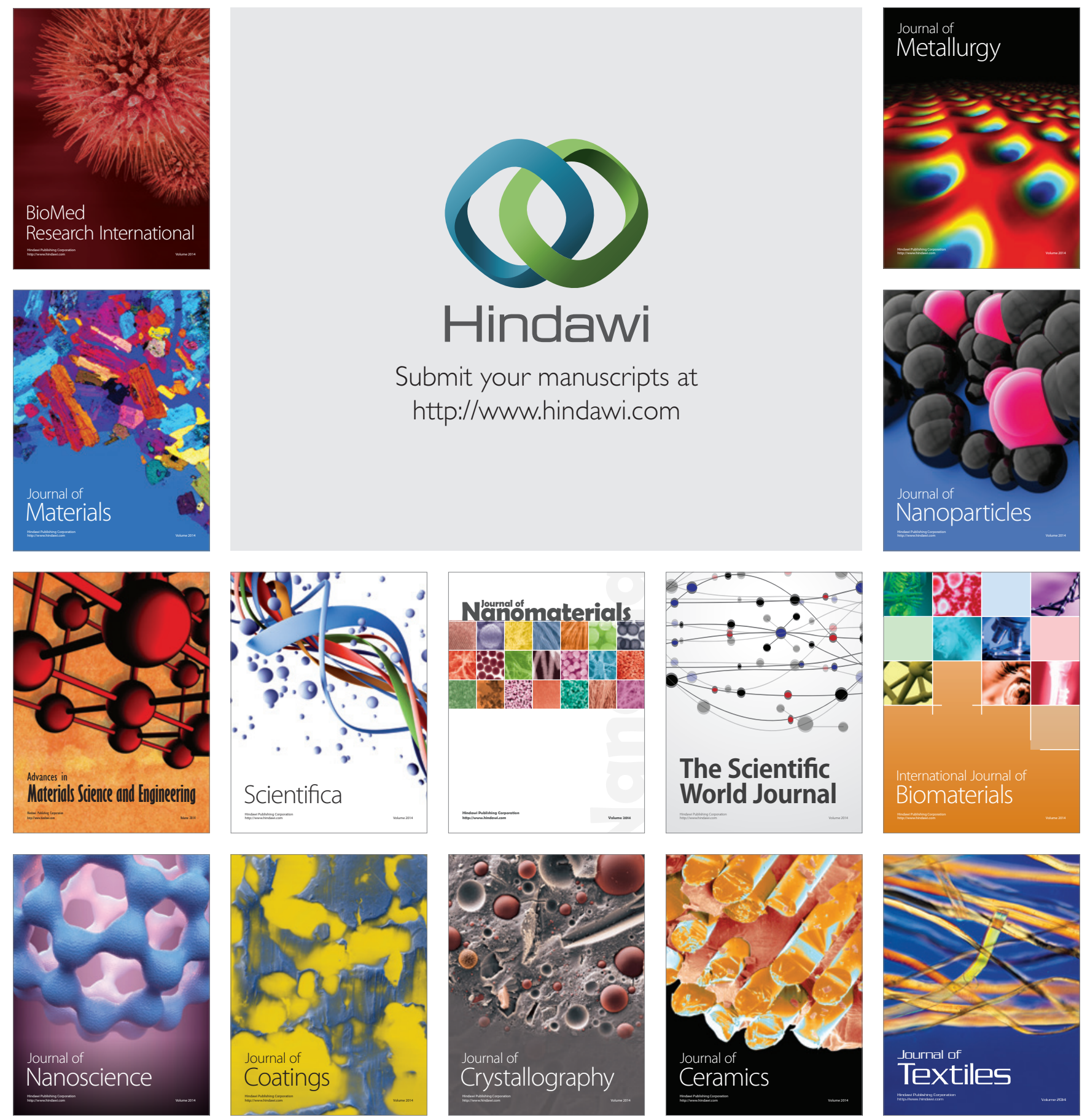